\title{
Corporate Social Responsibility sebagai Pemoderasi Pengaruh Ukuran Perusahaan terhadap Tax Aggressiveness
}

(Studi Empiris pada Perusahaan Manufaktur yang Terdaftar di Bursa Efek Indonesia Tahun 2015-2019)

\author{
Corporate Social Responsibility as A Moderator the Effect of \\ Firm Size on Tax Aggressiveness \\ (Empirical Study on Manufacturing Companies Listed on the Indonesia Stock Exchange \\ 2015-2019)
}

\author{
Dewi Kusuma Wardani', Anita Primastiwi², Elsa Ayu Agustin ${ }^{3}$ \\ 1 Universitas Sarjanawiyata Tamansiswa - Yogyakarta \\ 2Universitas Sarjanawiyata Tamansiswa - Yogyakarta \\ 3Universitas Sarjanawiyata Tamansiswa - Yogyakarta \\ Email : d3wikusuma@gmail.com
}

\begin{abstract}
ABSTRAK
Penelitian ini bertujuan untuk mengetahui pengaruh ukuran perusahaan terhadap tax aggressiveness dengan moderasi corporate social responsibility. Penelitian ini bersifat data kuantitatif. Populasi yang digunakan dalam penelitian ini adalah perusahaan manufaktur yang terdaftar di Bursa Efek Indonesia (BEI) tahun 2015-2019. Pengambilan sampel penelitian ini menggunakan metode purposive sampling dan diperoleh 178 data laporan keuangan tahunan. Jenis data yang digunakan adalah data sekunder yang diperoleh dari www.idx.co.id. Penelitian ini menggunakan analisis regresi sederhana dan moderated regression analysis. Hasil regresi penelitian menemukan ukuran perusahaan tidak berpengaruh terhadap tax aggressiveness dengan nilai signifikansi 0,171 dan nilai t $-0,002$ dan adanya Corporate social responsibility mampu memperkuat pengaruh positif ukuran perusahaan terhadap tax aggressiveness dengan nilai signifikansi 0,011 dan nilai t 0,058.
\end{abstract}

Kata Kunci: ukuran perusahaan, tax aggressiveness, corporate social responsibility

\section{ABSTRACT}

This study aims to determine the effect of firm size on tax aggressiveness with moderation of corporate social responsibility. This research is quantitative data. The population used in this study are manufacturing companies listed on the Indonesia Stock Exchange (BEI) in 2015-2019. The sample of this research used purposive sampling method and obtained 178 annual financial report data. The type of data used is secondary data obtained from www.idx.co.id. This study uses simple regression analysis and moderated regression analysis. The regression results found that company size had no effect on tax aggressiveness with a significance value of 0.171 and a t value of -0.002 and the existence of corporate social responsibility was able to strengthen the positive influence of company size on tax aggressiveness with a significance value of 0.011 and a t value of 0.058 .

Keywords: firm size, tax aggressiveness, corporate social responsibility 


\section{PENDAHULUAN}

Masa globalisasi ini dijadikan opportunity bagi seluruh warga Indonesia untuk berproses melakukan pembangunan yang jauh lebih baik dibidang politik maupun ekonomi. Faktor penting yang menjadi pendukung keberlangsungan negara yaitu kualitas sumber daya manusia (Suhardjana, 2009). Indonesia memiliki SDM dan kekayaan melimpah serta sebagai lalu lintas yang strategis guna perdagangan seluruh dunia, sehingga di Indonesia banyak sekali perusahaan yang berdiri (Yanti \& Hartono, 2019). Mendirikan perusahaan di Indonesia memiliki keuntungan yaitu dapat meningkatkan pemasukan bagi negara melalui sektor pajak. Tetapi program pemerintah yang dijalankan sangat bertolak belakang dengan program perusahaan yang menginginkan pajak seminimal mungkin, sehingga tindakan agresivitas pajak banyak dilakukan oleh perusahaan.

Fenomena yang terkait dengan penghindaran pajak yaitu PT. Adaro Energy Tbk tahun 20092017. PT. Adaro diduga melakukan pembayaran pajak senilai 1,75 triliun jauh lebih rendah dibandingkan pajak yang sesungguhnya harus dibayarkan kepada Negara. Suatu perusahaan akan melakukan tindakan tax planning (perencanaan pajak) dengan memanfaatkan celah yang ada pada peraturan perpajakan, tetapi ada beberapa upaya yang muncul dalam melakukan pengindaran pajak dengan mengakali sistem pajak tersebut (finance.detik.com, 2019).

Adanya tax planning untuk melakukan penghindaran pajak yang dilakukan oleh perusahaanperusahaan membuat Indonesia menempati peringkat ke-11 dari 30 negara dengan perusahaan yang melakukan penghindaran pajak atau tax aggressiveness terbanyak di dunia. Masuknya Indonesia dengan menempati posisi ke-11 ini merupakan laporan dari penyidik IMF yang berdasarkan pada hasil survei dan analisa yang dilakukan oleh Universitas PBB. Tingginya tingkat penghindaran pajak yang dilakukan oleh perusahaan-perusahaan di Indonesia ini dikarenakan sebesar 6,48 miliar Dolar AS pajak tidak dibayarkan oleh perusahaan kepada Dirjen Pajak (Tribunnews.com, 2017).

Perusahaan dalam melakukan tax aggressiveness dapat dipengaruhi oleh faktor ukuran perusahaan. Ukuran perusahaan didefinisikan oleh Delgado, Rodriguez \& Arias (2012) sebagai suatu tingkatan skala besar atau kecilnya perusahaan yang dilihat berdasarkan besaran total penjualan, aset, jumlah karyawan, dan jumlah usaha yang dijalankan. Perusahaan berskala besar pasti akan menghadapi tingginya biaya politik. Kondisi ini membuat perusahaan akan lebih memilih suatu kebijakan akuntansi yang cenderung menurunkan keuntungan dibandingkan dengan mempertahankan laba, karena semakin tinggi laba yang dicapai perusahaan maka semakin tinggi beban pajak yang di setorkan kepada Dirjen Pajak (DJP). Pemilihan metode yang dapat menguragi laba perusahaan dilakukan oleh perusahaan besar yang agresif terhadap pajak dengan menangguhkan laba perusahaan waktu sekarang ke laba waktu yang akan datang yang bertujuan untuk meminimalisasikan biaya politik yang akan ditanggung oleh perusahaan besar (Wu et al, 2012).

Di sisi lain, pengungkapan CSR dipandang secara luas adalah untuk mempengaruhi persepsi masyarakat dan menutupi citra buruk suatu perusahaan. Pengungkapana CSR juga dapat dikatakan sebagai salah satu sarana bagi perusahaan untuk memperkuat hubungan baik antara manajemen perusahaan dengan masyarakat luas (Lanis \& Richardson, 2013). Dengan adanya pengungkapan CSR yang semakin transparan dan juga luas, maka perusahaan berskala besar harus berhati-hati di dalam melakukan tax aggressiveness. Kehati-hatian ini diperlukan agar tax aggressiveness yang dilakukan oleh perusahaan tidak menimbulkan citra buruk perusahaan yang dapat menimbulkan hubungan tidak baik antara perusahaan dengan masyarakat dan stakeholder. Hubungan antara perusahaan dengan masyarakat dan stakeholder perlu dibangun dengan baik agar keberlangsungan usaha perusahaan tetap terjaga dan perusahaan dapat beroperasi 
sebagaimana mestinya dalam periode yang panjang (Prameswari, 2017). Fenomena adanya tax aggressiveness dan faktor-faktor yang mempengaruhi timbulnya tax aggressiveness tersebut, maka perlu diteliti mengenai pengaruh ukuran perusahaan terhadap tax aggressiveness dengan menggunakan corporate social responsibility sebagai pemoderasi

\section{LANDASAN TEORI}

\section{Positive Accounting Theory}

Teori akuntansi positif memiliki sifat yang aktual dan positif berfungsi untuk memperoleh suatu pembuktian/penjelasan yang benar tentang praktik di bidang akuntansi dari waktu ke waktu dengan cara memprediksi adanya tindakan atas kebijakan akuntansi. Hal itu berguna bagi perusahaan untuk memaksimalkan suatu kepentingan para pemangku jabatan (Andhari \& Sukartha, 2017). Makalah yang ditulis Watts \& Zimmermen (1990) dengan judul "Positive Accounting Theory: A Ten Years Perspective" menyatakan bahwa terdapat 3 (tiga) hipotesis yang berhubugan dengan kebijakan akuntansi, yaitu:

1) Bonus Plan Hypothesis menduga bahwa manajer akan memperoleh kompensasi bonus yang tinggi jika laba pada periode saat ini tinggi dengan cara memindahkan laba periode yang akan datag ke periode saat ini, sehingga pemilihan kebijakan akuntansi itu sangat penting.

2) Debt Covenant Hypothesis menjelaskan bahwa manajer perusahaan akan melanggar perjanjian utang, maka dar itu manajer harus memilih kebijakan yang memaksimalkan laba agar manajemen perusahaan dapat melunasi utang sehingga dapat memperkecil pelanggaran perjannjian utang.

3) Political Cost Hypothesis menjelaskan bahwa metode yang dipilih perusahaan yaitu menyerah pada laba yang memiliki tujuan agar perusahaan dapat memperkecil biaya politik yang ditanggung pemerintah termasuk pajak penghasilan dengan menangguhkan laba waktu saat ini ke laba yang akan datang (Watts \& Zimmerman, 1990).

Teori political cost hypothesis menerangkan semakin besarnya ukuran perusahaan akan lebih dipandang lebih special oleh publik karena besarnya suatu perusahaan akan lebih menghadapi tingginya biaya politik yang bertolak belakang dengan perusahaan kecil, sehingga lebih memilih kebijakan akuntansi yang menurunkan profit.

\section{Legitimacy Theory}

Legitimacy theory menerangkan mengenai peran teori tersebut pada perusahaan atau perilaku organisasi yaitu membantu pelaksanaan tugas perusahaan, melakukan pengembangan terhadap pengungkapan tanggung jawab sosial perusahaan, dan juga mengawasi hasil dari pemilihan kebijakan tanggung jawab sosial (Zyznarska \& Dworczak, 2018). Ratmono \& Sagala (2016) menyatakan bahwa pengungkapan CSR sebagai sarana legitimasi dapat berdampak terhadap tingkat pajak yang agresif. Penelitian tersebut menjelaskan bahwa baik atau tidaknya nilai perusahaan dapat diukur dari pengungkapan nilai sosial perusahaan tersebut. Adanya tanggung jawab sosial perusahaan yang lebih terbuka, luas, dan transparan kepada publik akan membuat perusahaan besar lebih berhati-hati dalam melakukan tax aggressiveness. Tax aggressiveness dapat menyebabkan persepsi tidak percaya oleh publik kepada perusahaan.

\section{Tax Aggressiveness}

Hlaing (2012) mengartikan tax aggressiveness merupakan tindakan penghindaran pajak yang dilakukan secara legal/ilegal oleh perusahaan dengan cara melakukan perencanaan pajak 
(tax planning) sehingga dapat mengurangi beban pajak perusahaan. Suatu perusahaan yang melakukan tax aggressiveness tersebut akan terlibat dalam meminimalkan tarif pajak yang berlaku di Indonesia guna mendapatkan profit yang tiggi dengan memanfaatkan celah peraturan perpajakan dengan memanfaatkan biaya-biaya yang dapat dijadikan sebagai pengurang pajak (Kuriah et al, 2016).

\section{Ukuran Perusahaan}

Ukuran perusahaan dibagi menjadi 3 kelompok yaitu small firm, medium firm, dan large firm dapat menyebabkan penghindaran pajak dan mampu mempengaruhi dalam melunasi kewajiban pajak (Dewinta \& Setiawan, 2016). Perusahaan yang termasuk dalam skala besar akan besar pula kemungkinannya untuk melakukan tax aggressiveness, sehingga semakin kecil beban pajak yang ditanggung perusahaan, karena laba perusahaan periode sekarang akan ditangguhkan ke periode selanjutnya (Adnyani \& Astika, 2019).

\section{Corporate Social Responsibility}

Corporate social resposibility (CSR) merupakan salah satu media untuk meningkatkan reputasi perusahaan dan mendapatkan kepercayaan publik kembali, maka pengungkapan CSR sangat penting dan bermafaat bagi perusahaan yang sedang beroperasi (Ratmono \& Sagala, 2016). Pengungkapan CSR bisa saja hanya untuk mengubah persepsi masyarakat luas dalam upaya untuk mendapatkan dukungan laba, mempertahankan nama baik perusahaan, dan menyembunyikan citra buruk perusahaan. Banyak perusahaan yang saat ini memenuhi kewajibannya dalam pembayaran pajak hanya untuk meningkatkan dan mempertahankan reputasi perusahaan. Salah satu konsep untuk melihat CSR suatu perusahaan bagi masyarakat luas baik di dalam maupun di luar perusahaan adalah dengan mencermati pelaporan informasi CSR di Indonesia (Pradipta, 2015). Pelaporan CSR dapat diukur dengan berdasarkan pada G4 Global Reporting Initiative (GRI-G4).

\section{Pengembangan Hipotesis}

\section{Pengaruh Ukuran Perusahaan Terhadap Tax Aggressiveness}

Positive accounting theory yang di dalamnya terdapat political cost hypothesis memprediksi bahwa semakin besar ukuran perusahaan pasti akan berhadapan pada tingginya biaya politik, sehingga perusahaan tersebut lebih memilih metode akuntansi yang dapat menurunkan profit (Windaswari \& Merkusiwati, 2018). Penggunaan metode yang dapat menurunkan profit akan menyebabkan semakin kecilnya pajak yang dibayarkan oleh perusahaan, karena profit periode saat ini ditangguhkan ke periode berikutnya. Hal tersebut termasuk dalam tindakan tax aggressiveness, dimana perusahaan akan melakukan tax planning agar beban pajak yang dibayarkan suatu perusahaan menjadi semakin kecil. Ketika beban pajak yang ditanggung perusahaan dapat diturunkan, maka perusahaan akan memiliki kesempatan yang cukup besar untuk melakukan perencanaan pajak yang baik dengan melakukan praktik akuntansi yang efektif dan efisien (Rodriguez dan Arias, 2012). Dengan demikian, semakin besar ukuran perusahaan maka semakin besar pula kemungkinan perusahaan untuk melakukan tax aggressiveness. Pandangan ini didukung oleh penelitian terdahulu yang telah dilakukan oleh Harjito, Sari \& Yulianto (2017), Hazir (2019), dan Adnyani \& Astika (2019) yang menunjukkan bahwa terdapat pengaruh positif antara ukuran perusahaan terhadap tax aggressiveness. Berdasarkan uraian di atas dapat dirumuskan hipotesis sebagai berikut:

\section{H1: Pengaruh positif ukuran perusahaan terhadap tax aggressiveness}




\section{Corporate Social Responsibility Dapat Memperlemah Pengaruh Ukuran Perusahaan Terhadap Tax Aggressiveness}

Variabel corporate social responsibility dapat dikaitkan dengan legitimacy theory yang menyatakan bahwa perusahaan akan memperoleh profit dan dituntut untuk memberikan perhatian kepada masyarakat (Prameswari, 2017). CSR bertujuan menigkatkan kesejahteraan kehidupan suatu Negara melalui perusahaan yang diharuskan memberikan kepedulian kepada masyarakat dan pemerintah. CSR memberikan berbagai informasi dan manfaat perusahaan seperti profit yang tinggi dalam melaporkan laporan keuangan lengkap setiap periodenya, dapat di percaya dan ketidakpastian yang terjadi pada perusahaan semakin kecil di masa depan (Lanis \& Richardson, 2017).

Tindakan tax aggressiveness biasanya cenderung dilakukan oleh ukuran perusahaan yang besar. Perusahaan yang besar akan mengungkapkan CSR yang tinggi karena perusahaan yang berskala besar akan berusaha untuk menutupi citra buruk perusahaan dengan memanipulasi laporan CSR. Hal tersebut dalam jangka waktu yang pendek berakibat perusahaan tidak bisa bertanggung jawab atas laporan yang telah dibuat jika suatu saat laporan itu diketahui oleh publik maupun stakeholder apa yang sesungguhnya telah terjadi (Liana \& Sari, 2017).

Adanya pengungkapan CSR pada perusahaan semakin transparan,serta luas, maka suatu perusahaan akan cenderung berhati-hati dalam melakukan program tax aggressiveness. Dengan membangun hubungan yang baik kepada masyarakat dan stakeholder, maka dalam jangka waktu yang panjang perusahaan dapat tetap beroperasi (Prameswari, 2017). Uraian yang dipaparkan di atas dapat dirumuskan hipotesis sebagai berikut:

\section{H2 : Corporate social responsibility dapat memperlemah pengaruh positif ukuran perusahaan terhadap tax aggressiveness}

\section{METODOLOGI PENELITIAN}

\section{Jenis dan Sumber Data Penelitian}

Sifat penelitian yang digunakan merupakan bentuk penelitian kuantitatif. Penelitian ini menggunakan jenis data sekunder, sehingga penelitian dalam bentuk angka.. Data tersebut terdapat pada perusahaan manufaktur dalam bentuk laporan keuangan tahunan yang telah terdaftar di Bursa Efek Indonesia melalui situs www.idx.co.id selama tahun 2015-2019. Populasi dalam penelitian ini menggunakan seluruh perusahaan manufaktur yang terdaftar di Bursa Efek Jakarta (BEI) tahun 2015-2019. Adapun teknik pengambilan sampel dilakukan dengan purposive sampling. Sampel diperolehl 178 data laporan keuangan tahunan dengan 48 perusahaan.

\section{Metode Analisis dan Hipotesisi Penelitian}

Pegujian penelitian ini menggunakan uji statistik deskriptive, uji asumsi klasik, uji analisis regresi linear sederhana, dan moderated regression analysis. Uji asumsi klasik dalam penelitian ini terdiri dari uji normalitas, multikolinearitas, autokorelasi dan heteroskedastisitas. Pengujian hipotesis untuk mengetahui pengaruh variabel independen pada variabel dependen menggunakan model analisis regresi linear sederhana, sedangkan pengujian untuk variabel moderasi menggunakan analisis moderated regression analysis (MRA).

\section{Operasional Variabel Penelitian}

Operasional variabel penelitian ini menggunakan variabel bebas yaitu ukuran perusahaan Variabel terikat pada penelitian ini yaitu tax aggressiveness ( $\mathrm{Y}$ ), dan pada penelitian ini menggunakan corporate social responsibility (Z).sebagai variabel pemoderasi. 


\section{Tax Aggressiveness}

Tax aggressiveness diukur menggunakan proksi utama yaitu proksi Effective Tax Rate (ETR). ETR dianggap mencerminkan perbedaan tetap antara laba fiskal dengan perhitungan laba buku (Ayu et al, 2015). Adanya agresivitas pajak ditunjukkan dengan rendahnya nilai ETR di perusahaan. Rendahnya nilai ETR menunjukkan semakin kecilnya beban pajak penghasilan yang dibayarkan dibandingkan dengan laba sebelum pajak. Penelitian ini mengacu pada penelitian yang dilakukan oleh Yanti \& Hartono (2019) dan Natalya (2018) yang pengukurannya dirumuskan sebagai berikut:

ETR $=\underline{\text { Total Beban Pajak Penghasilan }}$

Laba Sebelum Pajak

\section{Ukuran Perusahaan}

Proksi yang digunakan dalam variabel ukuran perusahaan ini menggunakan Log natural (sales). Total penjualan dimungkinkan dapat mengukur skala besar atau kecilnya suatu perusahaan sehingga dapat memberikan efek pada tax aggressiveness. Secara matematis size sales sebagai proksi dari ukuran perusahaan menurut Cahyadi et al (2020) adalah sebagai berikut:

SIZE = Log natur $\$$ Sale $\$$

\section{Corporate Social Responsibility}

Pengungkapan CSR bertujuan untuk pembangunan yang berkelanjutan yang mencakup lingkup sosial, ekonomi, dan lingkungan (Ayu et al, 2015). Pada penelitian ini standar Global Reporting Initiative (GRI-G4) digunakan untuk mengukur pengungkapan CSR dengan jumlah 91 indikator. Pada Gri-G4 indikator pengungkapan dibagi menjadi beberapa kategori yaitu ekonomi, lingkungan, tanggung jawab atas produk, masyarakat, sosial, dan hak asasi manusia. Pengungkapan CSR menggunakan rumus sebagai berikut:

$\Sigma \mathrm{CSRDi}=\sum \mathrm{Xi}$

$n$

CSRDi : Indeks luas pengungkapan CSR

$\Sigma X i \quad$ : Jumlah item bernilai 1 pada perusahaan.

$\mathrm{n} \quad$ : Jumlah item indikator pengungkapan CSR $(\mathrm{n}=91)$.

\section{HASIL DAN PEMBAHASAN \\ Hasil Penelitian}

Pengujian pada hipotesis pertama menggunakan analisis regresi linear sederhana yang digunakan untuk membuktikan suatu hubungan fungsional satu variable terikatnya. Dapat ditunjukkan dari hasil tabel dibawah menunjukkan nilai $\mathrm{R}^{2}$ sebesar 0,005 yang memberikan penjelasan bahwa ukuran perusahaan terhadap tax aggressiveness memiliki pengaruh sebesar 0,5\% sisanya $99,5 \%$ dapat digambarkan oleh variabel bebas lainnya. Hasil uji output SPSS dapat dibuktikan dalam tabel sebagai berikut: 


\section{Tabel 1. Hasil Uji Hipotesis Penelitian} Analisis Regresi Linear Berganda

\begin{tabular}{lccccc}
\hline \multicolumn{5}{c}{$\begin{array}{c}\text { Unstandardized } \\
\text { Coefficients }\end{array}$} & $\begin{array}{c}\text { Standardized } \\
\text { Coefficients }\end{array}$ \\
Model & $B$ & Std. Error & Beta & $t$ & \multicolumn{1}{c}{ Sig. } \\
\hline 1 (Constant) &, 301 &, 037 & & 8,095 &, 000 \\
Size Firm &,- 002 &, 001 &,- 103 & $-1,375$ &, 171 \\
\hline R Square & & & & 0,011 \\
Adjusted R Square & & & 0,005 \\
F hitung & & & 1,889 \\
Signifikansi & & & 0,171 \\
\hline Sumber Data: BEl, diolah dengan SPSS 20, (2020) & &
\end{tabular}

Hasil uji $\mathrm{F}$ dalam penelitian ini menunjukkan hasil $\mathrm{F}$-hitung 1,889 dan nilai signifikan sebesar 0,171 . Hal ini memberikan kesimpulan bahwa nilai sig jauh diatas 0,05 maka hipotesis ditolak, artinya variabel independen ukuran perusahaan tidak memiliki pengaruh terhadap tax aggressiveness, dengan kata lain model dinyatakan tidak fit.

Berdasarkan tabel 1 dapat dilihat bahwa variabel ukuran perusahaan tidak memiliki pengaruh terhadap tax aggressiveness pada tingkat signifikansi $5 \%$. Ukuran perusahaan memiliki nilai signifikan sebesar 0,171>0,05 dengan nilai t statistik sebesar $-1,375$ dan nilai $B$ sebesar 0,002. Dengan demikian, dapat disimpulkan bahwa tidak adanya pengaruh ukuran perusahaan terhadap tax aggressiveness, sehingga hipotesis yang menyatakan ukuran perusahaan berpengaruh positif terhadap tax aggressiveness tidak terdukung. Variabel ukuran perusahaan tidak memiliki pengaruh terhadap tax aggressiveness. Hasil penelitian ini didukung oleh penelitian terdahulu yaitu Djohar \& Rifkhan (2019), Mutmainah (2018), Windaswari \& Merkusiwati (2018) yang meghasilkan hasil penelitian yaitu tidak memiliki pengaruh ukuran perusahaan terhadap tax aggressiveness.

Pengujian hipotesis kedua untuk variabel moderasi menggunakan moderated regression analysis (MRA) yang digunakan untuk membuktikan suatu hubungan variable terikat dengan adanya variabel moderasi. Dapat dilihat dari hasil tabel dibawah menunjukkan nilai $\mathrm{R}^{2}$ sebesar 0,030 yang memberikan penjelasan bahwa variabel tax aggressiveness dijelaskan oleh variabel ukuran perusahaan dan corporate social responsibility memiliki pengaruh sebesar $3 \%$ dan sisanya $97 \%$ dapat dijelaskan oleh variabel lain diluar penelitian ini.

Output hasil uji SPSS dapat dilihat dalam tabel sebagai berikut:

Tabel 2. Hasil Uji Hipotesis Penelitian

Moderated Regression Analysis

\begin{tabular}{cccccc}
\hline \multicolumn{7}{c}{$\begin{array}{c}\text { Unstandardized } \\
\text { Coeffi cients }\end{array}$} & $\begin{array}{c}\text { Standardized } \\
\text { Coefficients } \\
\text { Beta }\end{array}$ & \multicolumn{1}{c}{$T$} & \multicolumn{1}{c}{ Sig. } \\
\hline 1 (Constant) & Std. Error & & Beta & & \\
Size Firm &, 549 &, 103 & & 5,308 &, 000 \\
CSR & $-1,010$ &, 004 &,- 604 & $-2,901$ &, 004 \\
X1Z & $-1,700$ &, 671 & $-3,298$ & $-2,536$ &, 012 \\
\hline R Square &, 058 &, 023 & 3,498 & 2,557 &, 011 \\
\hline
\end{tabular}




\begin{tabular}{ll} 
Adjusted R Square & 0,030 \\
F hitung & 2,855 \\
Signifikansi & 0,039 \\
\hline
\end{tabular}

Sumber Data: BEI, Diolah dengan SPSS 20, (2020)

Hasil uji F pada pengujian MRA ini menunjukkan bahwa bahwa F-hitung 2,855 dan nilai signifikan sebesar 0,039 . Hal ini menyatakan bahwa nilai sig dibawah 0,05 , artinya variabel independen ukuran perusahaan, corporate social responsibility, dan X1Z berarti memiliki pengaruh terhadap tax aggressiveness, dengan kata lain model dinyatakan sudah fit.

Berdasarkan tabel 2 hasil uji T pada analisis MRA menunjukkan bahwa secara individu variabel ukuran perusahaan memiliki nilai koefisien $-0,010$ dan nilai $t$ sebesar $-2,901$ dengan probabilitas signifikansi 0,004 jauh dibawah 0,05 . Variabel corporate social responsibility memiliki nilai koefisien $-1,700$ dan nilai t statistik sebesar $-2,538$ dengan probabilitas signifikansi 0,012 jauh dibawah 0,05 . Kedua variabel ini dapat disimpulkan memiliki pengaruh negative terhadap effective tax rate (ETR) atau berpengaruh positif terhadap tax aggressiveness. Variabel X1Z menunjukkan hasil nilai signifikansi $0,011<0,05$, nilai koefisiennya sebesar 0,058 , dan nilai t sebesar 2,557 dapat disimpulkan bahwa variabel corporate social responsibility dapat memperkuat pengaruh positif ukuran perusahan terhadap tax aggressiveness, sehingga hipotesis yang menyatakan bahwa corporate social responsibility dapat memperkuat pengaruh positif ukuran perusahaan terhadap tax aggressiveness ditolak. Variabel tanggung jawab sosial perusahaan dapat memperkuat pengaruh positif ukuran perusahaan terhadap tax aggressiveness. Hasil penelitian ini didukung oleh penelitian Aalin (2018) dan Lanis \& Richardson (2017) menemukan bahwa tingginya pengungkapan CSR berpengaruh dalam tindakan tax aggressiveness.

\section{REKOMENDASI KEBIJAKAN}

\section{Rekomendasi}

Berdasarkan hasil penelitian yang telah dilakukan pengujian data menggunakan SPSS V.20 sesuai dengan tujuan penelitian ini, maka adapun rekomendasi hasil dari penelitian ini sebagai berikut:

1. Hal ini menunjukkan bahwa ukuran perusahaan tidak memiliki pengaruh dalam menentukan tinggi rendahnya perusahaan dalam melakukan tax aggressiveness. Hasil tersebut menunjukkan semakin besar suatu perusahaan, maka tidak akan mempengaruhi perusahaan dalam melakukan tindakan tax aggressiveness. Ketika total sales semakin tinggi yang menandakan bahwa perusahaan itu semakin besar maka perusahaan yang besar akan dipandang utama oleh publik dan memiliki going concern yang lebih bagus,. Pperusahaan besar akan lebih mengungkapkan kondisinya secara akurat, sehingga akan memiliki peluang yang kecil dalam memanipulasi laba dibandingkan dengan perusahaan yang lebih kecil (Mutmainah, 2018).

2. Adanya pengungkapan CSR akan berdampak pada tingkat perlakuan perusahaan dalam melakukan tax aggressiveness. Perusahaan yang memiliki ukuran perusahaan dalam skala besar akan lebih cenderung memilih memgungkapkan CSR guna untuk menutupi perusahaan yang telah melakukan tax aggressiveness. Semakin tinggi CSR pada suatu perusahaan maka semakin baik pula persepsi masyarakat pada perusahaan. 


\section{Kebijakan}

Penelitian ini menguji pengaruh ukuran perusahaan terhadap tax aggressiveness dengan corporate social responsibility sebagai pemoderasi. Berdasarkan hasil penelitan ini dan interpretasi penelitian ini, maka peneliti dapat ditarik beberapa saran sebagai rekomendasi kebijakan antara lain :

1. Penelitian selanjutnya bisa meneliti dengan objek penelitian yang berbeda guna untuk memperoleh perbandingan dengan jenis industri yang berbeda misalnya di sektor perbankan, infrastruktur, property dan real estate guna.

2. Penelitian selanjutnya sebaiknya dilakukan pengkajian dari beberapa penelitian sebelumnya dan diharapkan dapat menambah atau mengganti variabel independen sehingga memungkinkan untuk mendapatkan hasil penelitian yang lebih baik dalam menjelaskan variasi variabel tax aggressiveness, seperti menambah variabel profitabilitas, likuidasi, capital intensity, invetory intensity dan leverage.

3. Penelitian selannjutnya diharapkan dapat menambah jangka waktu penelitian lebih dari 5 (lima) tahun sehingga data dapat lebih memperlihatkan kondisi perusahaan yang sebenarnya.

\section{DAFTAR PUSTAKA}

Aalin, E. R. (2018). Pengaruh pengungkapan tanggung jawab sosial perusahaan terhadap agresivitas pajak. 3(2). Jurnal Politeknik Kediri.

Andhari, P. A. S., \& Sukartha, I. M. (2017). Pengaruh Pengungkapan Corporate Social Responsibility, Profitabilitas, Inventory Intensity, Capital Intensity Dan Leverage Pada Agresivitas Pajak. E-Jurnal Akuntansi Universitas Udayana, 18(03), 2115-2142.

Ayu, I. D., Pradnyadari, I., \& Rohman, A. (2015). Pengaruh Pengungkapan Corporate Social Responsibility Terhadap Agresivitas Pajak. Diponegoro Journal of Accounting, 4(2003), 19.

Delgado, F. J., Rodriguez, E. F., \& Arias, A. M. (2012). Size and Other Determinants of Corporate Effective Tax Rates in US Listed Companies. International Research Journal of Finance and Economics, (98), 160-165.

finance.detik.com. (2019). Mengenal soal Penghindaran Pajak yang Dituduhkan ke Adaro. In https://finance.detik.com/berita-ekonomi-bisnis/d-4612708/mengenal-soalpenghindaranpajak-yang-dituduhkan-ke-adaro.

Harjito, Y., Sari, C. N., \& Yulianto, -. (2017). Tax Aggressiveness Seen From Company Characteristics and Corporate Social Responsibility. Journal of Auditing, Finance, and Forensic Accounting, 5(2), 77. https://doi.org/10.21107/jaffa.v5i2.3765

Hazir, A. (2019). Determinants Of Eferctive Tax Rates In Turkey. Determinants Of Eferctive Tax Rates In Turkey.

Hlaing, K. P. (2012). Organizational Architecture of Multinationals and Tax Aggressiveness, University of Waterloo. Canada.

Kadek Ari Adnyani, N., \& Bagus Putra Astika, I. (2019). Pengaruh Profitabilitas, Capital Intensity, dan Ukuran Perusahaan Pada Tax Aggressive. E-Jurnal Ekonomi Dan Bisnis Universitas Udayana, 6, 594. https://doi.org/10.24843/eeb.2019.v08.i06.p04

Kuriah, Lailatul, H., \& Asyik, N. F. (2016). Jurnal. Pengaruh Karakteristik Perusahaan Dan Corporate Social Responsibility Terhadap Agresivitas Pajak. 
Lanis, R., \& Richardson, G. (2017). Corporate social responsibility and tax aggressiveness: A test of legitimacy theory. Accounting, Auditing and Accountability Journal, 26(1), 75-100. https://doi.org/10.1108/09513571311285621

Mutmainah, L. (2018). Pengaruh Pengungkapan Proitabilitas dan Ukuran Perusahaan Terhadap Agresivitas Pajak.

Natalya, D. (2018). Pengaruh Capital Intensity, Leverage dan Profitabilitas Terhadap Tax Aggressiveness dengan Kinerja Pasar sebagai Variabel Moderating. Media Akuntansi Perpajakan, 3(1), 37-55.

Prameswari, F. (2017). Pengaruh Ukuran Perusahaan Terhadap Agresivitas Pajak Dengan Corporate Social Responsibility Sebagai Variabel Moderasi. Jurnal Ekonomi Akuntansi, 3(4), 74-90. Retrieved from fe.ubhara.ac.id

Ratmono, D., \& Sagala, W. M. (2016). Pengungkapan Corporate Social Responsibility (CSR) Sebagai Sarana Legitimasi: Dampaknya Terhadap Tingkat Agresivitas Pajak. Nominal, Barometer Riset Akuntansi Dan Manajemen, 4(2), 16-30. https://doi.org/10.21831/nominal.v4i2.7997

Rosa Dewinta, I., \& Ery Setiawan, P. (2016). Pengaruh Ukuran Perusahaan, Umur Perusahaan, Profitabilitas, Leverage, Dan Pertumbuhan Penjualan Terhadap Tax Avoidance. E-Jurnal Akuntansi, 14(3), 1584-1615.

Suhardjana, J. (2009). Kualitas Sumber daya Manusia Menentukan Kemajuan Suatu Negara. Jurnal Dinamika Hukum, 9(3), 268-275. https://doi.org/10.20884/1.jdh.2009.9.3.238

Tribunnews.com. (2017). Indonesia Masuk Peringkat ke-11 Penghindaran Pajak Perusahaan, Jepang No.3. In https://www.tribunnews.com/internasional/2017/11/20/indonesiamasukperingkat-ke-11-penghindaran-pajak-perusahaan-jepang-no3.

Watts, R. L., \& Zimmerman, J. L. (1990). Accounting Year Theory: Ten Perspective. Review Literature And Arts Of The Americas, 65(1), 131-156. https://doi.org/10.2307/247880

Watts, \& Zimmermen. (1990). Positive Accounting Theory: A Ten Years Perspective. Positive Accounting Theory: A Ten Years Perspective. The Accounting Review, Vol. 65, N.

Windaswari, K. A., \& Merkusiwati, N. K. L. A. (2018). Pengaruh Koneksi Politik, Capital Intensity, Profitabilitas, Leverage dan Ukuran Perusahaan Pada Agresivitas Pajak. E-Jurnal Akuntansi, 23, 1980. https://doi.org/10.24843/eja.2018.v23.i03.p14

Wu, L., Wang, Y., Luo, W., \& Gillis, P. (2012). State ownership, tax status and size effect of effective tax rate in China. Accounting and Business Research, 42(2), 97-114. https://doi.org/10.1080/00014788.2012.628208

Yanti, L. D., \& Hartono, L. (2019). Effect of Leverage, Profitability and Company Size on Tax Aggressiveness. (Empirical Study : Subsector Manufacturing Companies Food, Beverage, Cosmetics and Household Purposes Manufacturing Listed on the Indonesia Stock Exchange for. ECo-Fin, 1(1). https://doi.org/10.32877/ef.v1i1.52

Zyznarska-Dworczak, B. (2018). Legitimacy Theory in Management Accounting Research. Problemy Zarzadzania, 16(1(72)), 195-203. https://doi.org/10.7172/1644-9584.72.12 